\title{
Analysis of the Influence of International Trade Flow Based on Trade Gravity Model and Statistics in as Evidence
}

\author{
YANG Yong ${ }^{1, a}$ \\ 1 Jiangxi college of foreign study,NanChang,330099 China \\ a YangYong1029@yeah.net
}

Keywords: Free Trade Area; Gravity Model; Trade Flow

\begin{abstract}
In recent years, faced with an increasingly globalized economy, China has carried out the strategy of free trade area, drawing the eyes of the entire world. In this paper, trading statistics of China and its 14 trading partners from 2000 to 2010 is taken as sample and a gravity model is expanded by adding variables including the access to free trade agreement to conduct a case analysis to the influence of international trade flow. According to the statistics, the economic size, population, culture and trading regime are all imposing much impact on China's international trade. Indeed, the establishment of free trade area contributes a lot to the trading flow of between China and its trading partners as opposed to the dramatic negative impact of distance to its trade flow.
\end{abstract}

\section{Introduction}

Since 1990s, regional economic integration was strengthened thanks to the rapidly globalized economy. Confronted with an unsteady economic recovery and frustrated multilateral trading negotiations, bilateral and regional economic liberalization is widely pursued, featuring the booming free trade area. Its boom across the world not only comes from the trade-creating effect brought by its cut of tariff but also the following effect brought by the flow of funds, service and human resources. Its establishment is also a reflection of the political wills of strengthening regional cooperation which is conducive to improving political relations, creating favorable environment and enhancing the confidence of businesses within the region to invest and trade. These edges stand out against the global context that the world economic recovery has a long way to go and that economic policies of the countries are yet to suit each other. Therefore, in China's $12^{\text {th }}$ Five-Year Plan, the ideas of accelerating the implementation of free trade area strategy, enhance the economic ties between China and its trading partners, taking the sub-regional cooperation regime and strengthen the cooperation between China and other countries and regions are forged. This is proven that developing regional integration has received much attention of Chinese government. So far, China has signed or been in negotiation to develop 15 bilateral free trade areas in total covering 28 countries and regions from five continents. Today, China has signed and carried out its plans of free trade area with ASEAN, Chile, Pakistan, New Zealand, Peru and Costa Rita.

\section{Theoretical Review}

The classical and neo-classical trade theories prove that international trade benefits the economy and welfare of a country and explain how a country can get a share from international distribution by presenting its comparative edge in cost and its advantage in resources. In fact, China's economic performance is an evidence of this.

Although causes of international trade are found and ways of trade distribution are given in classical and neo-classical trade theories, determinants of trade flow are yet to be presented. Among a number of models and theories, the gravity model given in 1960s serves as an important tool to illustrate trade flow. The gravity model is known as that the trade flow among countries is proportional to their respective economic size, and inversely proportional to their distance. Its name comes from the physical law of Universal Gravitation, and simple as it is, it has been so successful that it was widely applied in international trade studies in areas in estimating trade potential and 
identifying effect of trading groups so that some daily economic phenomena were illustrated since 1960s.

Tinbergen and Poyhonen are the earliest scholars applying the model in international trade studies. They portrayed the model in its basic form as follows:

$$
T_{i j}=k Y_{i} Y_{j} / D_{i j}
$$

In the formula above, $k$ serves as a constant and $T_{i j}$ refers to the bilateral trade column between two countries and regions. Besides, $Y_{i}$ and $Y_{j}$ refer to the economic sizes of both countries and $D_{i j}$ refers to the distance between the countries (or regions), their economic centers or main ports in particular. Through studies, Tinbergen holds that trade flow from one country to another is mainly determined by their economic size measure by GDP and their distance to each other. According to his analysis of trading data 15 developed countries and 3 least developed countries in 1959, geographical distance has a dramatic impact on trade flow. In this way, the gravity model is able to illustrate at least $75 \%$ of all the trade volume. Poyhonen, however, went further by replacing distance with transport cost.

In later studies, the gravity model is also widely applied in analysis to the international trade flow which is largely improved during the time.

\section{Analysis Applying the Gravity Model Supported by China's Statistics}

\section{The Development of the Theory of Gravity Model}

Gravity Model is the application of Law of Universal Gravity in the field of international trade and it is used to reflect the impact of economic size and distance on world trade flow and destination. According to the study of Tinbergen and Poyhonen, the trade flow among countries is proportional to their respective economic size, and inversely proportional to their distance. Therefore, the gravity model can be portrayed in its basic form as follows:

$$
T_{i j}=k Y_{i} Y_{j} / D_{i j}
$$

In the formula above, $k$ serves as a constant and $T_{i j}$ refers to the bilateral trade column between two countries and regions. Besides, $Y_{i}$ and $Y_{j}$ refer to the economic sizes of both countries and $D_{i j}$ refers to the distance between the countries (or regions), their economic centers or main ports in particular. Later on, scholars including N.D.Aitken (1973) have included population into the model as one of the determinants. They hold that population is inversely proportional to trade flow. Scholars including Josef C. Brada and Jone A. Mendez have drown a different conclusion. They found that population, as opposed to the conclusion above, is proportional to trade flow. Herbert Glejser (1968) discovered in his analysis that the national income of exporters is inversely proportional to trade flow. Later on, more and more scholars added new factors such as language, culture and integrated organizations to illustrate their internal impact to trade flow. In this paper, variants are properly introduced or excluded so as to build a gravity model suitable to China's bilateral trade.

\section{Model Building and Variants Setting}

This paper takes the bilateral trade between China and 14 other economies including Hong Kong, India, Singapore, Malaysia, Japan, Pakistan, South Korean, Taiwan, the United States, Canada, Germany, Brazil and Chile and established a general gravity model and gravity trade models of import and export respectively in order to illustrate the impact of various factors on trade impact. Considering the diversity of samples and their complementarities of trade with China, the countries above were chosen as samples.

Based on the gravity model, taking possible effect of different impact on the developed countries and developing countries into consideration into consideration, the simulated common trading volume in total including the economic size of the traders and the virtual trade volume is also taken into consideration. This result can be shown as follows Fig 1: 


\begin{tabular}{|c|c|}
\hline Variants & Meanings \\
\hline $\operatorname{trade}_{i j t}$ & Bilateral trade volume between China and trading partner $\mathrm{j}$ in year $\mathrm{t}$ \\
\hline $\mathrm{ex}_{\mathrm{ij}}$ & Export volume from China to trading partner $\mathrm{j}$ in year $\mathrm{t}$ \\
\hline $\mathrm{im}_{\mathrm{ij}}$ & Import volume from China to trading partner $\mathrm{j}$ in year $\mathrm{t}$ \\
\hline $\operatorname{gdp}_{\mathrm{t}}^{*} \mathrm{fgdp}_{\mathrm{t}}$ & $\begin{array}{l}\text { Multiplied product of GDP of China and its trading partner counted by purchasing } \\
\text { capacity, showing the economic size of both sides }\end{array}$ \\
\hline pop $_{t * f p o p}$ & Multiplied product of total population between China and trading partner $\mathrm{j}$ in year $\mathrm{t}$ \\
\hline $\operatorname{dis}_{\mathrm{ij}}$ & Distance between central cities of China and trading partner $\mathrm{j}$ in year $\mathrm{t}$ \\
\hline $\mathrm{fta}_{\mathrm{ij}}$ & $\begin{array}{l}\text { Whether China signs FTA with trading partner } \mathrm{j} \text { in year } \mathrm{t} \text {, if no, it equals to } 0 \text {; if yes, } \\
\text { equals to } 1\end{array}$ \\
\hline $\mathrm{cul}_{\mathrm{ij}}$ & $\begin{array}{l}\text { Whether there is cultural intimacy between China and trading partner } \mathrm{j} \text {, if yes, it } \\
\text { equals to } 1 \text {; if no, equals to } 0\end{array}$ \\
\hline Fta*fgdp & Cross term of FTA virtual variants and economic aggregate of its trading partner \\
\hline
\end{tabular}

Fig 1 Model Building and Variants Setting

This paper takes the relevant data of 14 trade partners of China as an example from 2000 to 2010 . Considering the availability of the samples and the consistency of the sources, this data comes from the database of trade of the United States. The result of cultural virtual variants are all based on the definition of East-Asian Cultural Community given by 3ikipedia.com. All the region that used to, are and will be close to Chinese culture and politics and influenced by the Chinese history are all regarded as countries and regions in the shadow of Chinese culture. The FTA analysis of its variants come from the registered statistics in Secretariat of WHO (World Trade Organization) and the data of distance between both countries and regions comes from the famous geographical website www.geobyles.com. The descriptive data of variants are as follows Fig 2:

\begin{tabular}{|c|c|c|c|c|c|}
\hline Variants & Sample Number & Average & Standard Deviation & Min & Max \\
\hline $\ln _{\text {trade }}$ & 154 & 15.04 & 1.36 & 11.66 & 17.47 \\
\hline $\ln _{\max }$ & 154 & 14.25 & 1.43 & 11.11 & 17.16 \\
\hline $\ln _{\min }$ & 154 & 11.22 & 1.39 & 10.80 & 16.69 \\
\hline $\ln _{\text {(gdp } * \text { fgdp) }}$ & 154 & 15.41 & 1.35 & 12.91 & 18.81 \\
\hline $\ln _{\text {(pop*fpop) }}$ & 154 & 11.12 & 1.47 & 8.56 & 14.28 \\
\hline $\ln _{\text {dis }}$ & 154 & 8.5 & 0.87 & 6.86 & $9 / 86$ \\
\hline $\mathrm{fta}$ & 154 & 0.18 & 0.38 & 0 & 1 \\
\hline $\mathrm{cul}$ & 154 & 0.43 & 0.5 & 0 & 1 \\
\hline $\mathrm{fta}^{*} \ln _{\text {fgdp }}$ & 154 & 1.01 & 2.19 & 0 & 6.71 \\
\hline
\end{tabular}

Fig 2. Statistics of Variants of Gravity Model

\section{Conclusion}

This paper takes the trade data between China and its 14 trading partners from 2000 to 2010 to develop a model based on the old trade gravity model. In this way, impact of various factors on trade flow of China's bilateral trade under the free trade agreement is analyzed. It is shown that the trade flow is reliant on the economic size, the regime of the free trade area and the cultural environment. In fact, for the exporters, free trade agreement and cultural similarity contribute even more in their trade flow. On the other hand, the population size and distance between major cities is inversely proportional to the trade flow, and for the importers, distance plays a biggest role in exports.

China's experience during the three decades since reform and opening up is a persuasive evidence for the basic theory that international trade drives economic growth. Since it is so important to develop international trade, how is China expected to further develop its international trade to keep an ongoing economic growth based on the research?

First of all, preferential trade policies should be given to enhance bilateral trade between China and 
the rest of the world. APEC, as we all know, is providing a favorable chance to develop our international trade. Therefore, we have every reason to expect the impetus of China-ASEAN free trade area as the world's largest zero-tariff area.

Besides, China should also attach more importance to those countries and regions of huge economic size and much developing potential such as Brazil and India. As emerging markets, these economies boast vast domestic markets and promising prospect. In these countries, markets can be better satisfied by products of China which are both qualified and inexpensive. Moreover, the bilateral trade between China and African countries is yet to be developed, and the trading potential deserves much attention.

Finally, the industrial upgrading and technological progress of exporters require policy support from the government. Rodrik (2006) pointed out that support from Chinese government for electronics in the key that China goes much farther than other countries in its electronics exporting. Government support lowers exporters' risk when entering a new field to some degree. At the same time, it also sets up an example among all the exporters. All these help promote and apply technological progress.

\section{References}

[1] Wang Kailei. Factors Impacting International Trade Flow-A Case Analysis Based on Trade Gravity Model and Statistics in China [J]. World Economics, 2007,12:20-23.

[2] Chen Xin. Research to Mutual Impact between China's International Trade and Foreign Direct Investment [D]. Suzhou University, 2013.

[3] Xie Mengjun. Research to the Impact of Regimes of Destination on China's Options of Exporting and Investing Location [D]. Shandong University, 2014.

[4] Jiang Chenchun. A Case Study on Impact of Cultural Distance on China's Import and Export Trade [D]. Central South University, 2012. 